\title{
Biology of Eretmocerus sudanensis n. sp. Zolnerowich and Rose, parasitoid of Bemisia tabaci Gennadius
}

\author{
José A. Castillo • Philip A. Stansly
}

Received: 20 August 2010/ Accepted: 31 March 2011/Published online: 22 April 2011

(C) The Author(s) 2011. This article is published with open access at Springerlink.com

\begin{abstract}
Eretmocerus sudanensis $=E$. nr. emirates was released in 1992 into South Florida from Sudan to control Bemisia tabaci. It has since become the dominant Eretmocerus species in southwest Florida. Specimens were recovered at the Southwest Florida Research and Education Center in Collier County from a population of B. tabaci on collard Brassica oleracea, and the parasitoid described as new species, though as yet unpublished. Here we report results of studies conducted to evaluate the biology of this parasitoid of B. tabaci biotype B under laboratory controlled conditions $\left(26^{\circ} \mathrm{C} \pm 0.5,13 \mathrm{~h}\right.$ light, $\left.62 \% \pm 6 \mathrm{HR}\right)$. No preoviposition period was observed for E. sudanensis. Females lived an average of 13.2 days and in this time deposited an average of $161 \mathrm{eggs}$ at a mean oviposition rate of 13 eggs per day. The total compared favorably with published values for E. melanoscutus (123 eggs) and was similar to E. mundus (171 eggs). E. sudanensis showed the same tendencies of preference and suitability for the intermediate host stages (2nd and 3rd) as reported for these same 2 species. However, parameters such as development time from egg to adult (16 days)
\end{abstract}

Handling Editor: Torsten Meiners

J. A. Castillo - P. A. Stansly ( $\square)$

University of Florida/IFAS, Southwest Florida Research and Education Center, 2685 SR 29 N, Immokalee,

FL 34142, USA

e-mail: pstansly@ufl.edu and net reproductive rate ( $\mathrm{Ro}=91.3 \mathrm{eggs} / \mathrm{female})$ were shorter and greater, respectively, compared to published results for either E. melanoscutus or E. mundus under similar conditions. Such differences in demographic parameters could indicate a significantly greater reproductive potential for E. sudanensis.

Keywords Suitability - Development - Fecundity · Life table $\cdot$ Demographic parameters

\section{Introduction}

Bemisia tabaci Gennadius (Homoptera: Aleyrodidae) is a key pest of many horticultural and agronomic crops throughout the tropics and subtropics. Although this species was reported over 100 years ago in the US (Quaintance 1900) it did not rise to general pest status in the US until introduction and spread of the Old World "B" biotype in the late 1980s (Stansly and Naranjo 2010). In response, Old World species of aphelinid parasitoids in the genus Eretmocerus were released in the southern US during the 1990s, became established and largely displaced native congeners (Gould et al. 2008). Among these was a wasp collected in 1991 from Wadi Medani Sudan, designated Eretmocerus $n r$. emiratus and released in six Florida counties during 1991-1993 (Nguyen and Bennett 1995). Specimens collected by R. Nguyen (FDOAC-DPI Gainesville, FL, USA) in 2001 in 
Alachua County, FL and P. A. Stansly in 2003 in Collier County Florida were determined to be conspecific with this species (Zolnerowitz and Rose 2008) and were described as E. sudanensis (G. Zolnerowitz and M. Rose unpublished). Eretmocerus sudanensis appears to have completely replaced the native Eretmocerus sp. in the environs of Immokalee since surveys conducted in the previous decade (Stansly et al. 1997; Schuster et al. 1998; P. A. Stansly unpublished data).

Coincidentally Eretmocerus species for United Arab Republic and Ethiopia identified as Eretmocerus emiratus and E. nr. emiratus, respectively, were released in Arizona and California and became the dominant species on B. tabaci in the Phoenix area and the Imperial Valley (Gould et al. 2008; Roltsch et al. 2008). A recent comparison of $E$. nr emiratus from Arizona and E. sudanensis from Florida using RAPD PCR (Vacek et al. 2008) indicated a single band difference (Naranjo, personal communication).

Although E. nr emiratus and E. emiratus were top performers in field cage studies conducted in California (Hoelmer and Roltsch 2008) we could find no published reports on the biology of any species in the E. emiratus group. However, their success over a wide range of environmental conditions suggests that they may possess some especially useful traits for biological control of B. tabaci. Therefore, the present study was undertaken to evaluate and describe the biology and demographic parameters of E. sudanensis.

\section{Materials and methods}

\section{B. tabaci colony}

Whiteflies (B. tabaci biotype B) and parasitoids were collected in the field from tomato and collard November 2006 from which a colony was initiated and maintained in a small air-conditioned greenhouse on collard plants (var 'Georgia' TwilleySeed ${ }^{\circledR}$ Hodges, $\mathrm{SC}$, USA) grown in pots. Collard was chosen because the parasitoids seem to adopt well to this crop and because of its tolerance to varying environmental conditions and to whitefly infestation. Plants were seeded first into "Speedling" trays and after a month transplanted into 12.7 or $15.2 \mathrm{~cm}$ pots and grown for two months before being placed into a ventilated cage $(60 \times 60 \times 60 \mathrm{~cm})$ containing approximately
500 to 1000 whitefly adults in a room maintained at $25^{\circ} \mathrm{C}, 70 \% \mathrm{RH}, 13: 11 \mathrm{~h}$ (L:D). Plants were replaced with fresh plants as needed.

\section{E. sudanensis colony}

Four clean plants approximately three months of age were introduced for a $48 \mathrm{~h}$ oviposition period into the whitefly colony cage. Adult whiteflies were removed from four plants, each containing 3000-4000 2nd and early 3rd instar nymphs and placed in one of two wood frame cages $(60 \times 60 \times 60 \mathrm{~cm})$, covered with antithrips polyethylene mesh for ventilation in a separate rearing room at $26 \pm 1.5^{\circ} \mathrm{C}, 60 \pm 10 \% \mathrm{RH}$, 14:10 h (L:D) where the parasitoid colony was maintained. Wasps of both sexes (100-200) were then introduced for two weeks into the cages to parasitize the nymphs. Separate generations were maintained simultaneously in each of the two cages.

Host stage preference and suitability-no-choice test

Sets of rooted sweet potato slips and collard seedlings in $3^{\prime \prime}$-pots one and two months old, respectively, were exposed to whitefly adults for $24 \mathrm{~h}$. Adults were removed with an aspirator and seedlings enclosed individually in an inverted transparent plastic cup cage $\left(4.5 \times 3.5 \times 6^{\prime \prime}\right)$ covered on the upended base with antithrips screen for ventilation. Each cup was considered an experimental unit of which there were $n=16$ for each treatment (host instar).

Whiteflies were held in an incubator illuminated with fluorescent lights and maintained at $26^{\circ} \mathrm{C} \pm 0.5$ and $62 \% \pm 6 \mathrm{RH}, 13: 11 \mathrm{~h}$ (L:D) until the desired instars were obtained: 7, 8, 10 and 14 days for 1 st, 2nd, 3rd and 4th instars, respectively. Leaves were inspected prior to parasitoid exposure to remove undesired instars and to assure that an excess of desired instars was present. Parasitoids of both sexes recently emerged and mated were then introduced, two couples each, into the cup cages where they were provided with a drop of honey and water over the polyethylene mesh and allowed to parasitize for $24 \mathrm{~h}$. Data was not used if both females were not alive at the end of the parasitization period. Parasitism was evaluated under a stereoscopic microscope by inverting the nymphs with a fine needle to observe the presence or absence of a parasitoid egg. 
Choice tests

All environmental conditions were maintained as above. Collard seedlings were exposed to B. tabaci adults for seven days to have all nymphal stages together in each experimental unit. Whitefly adults were removed and seedlings incubated individually in cup cages for seven days, then inspected to determine whether enough nymphs were present. Parasitoids of both sexes recently emerged and mated were then introduced, two couples per cage, and left to parasitize for $24 \mathrm{~h}$. The number of parasitized and unparasitized nymphs of each instar was then recorded from all leaves as above.

Rooted sweet potato leaves in glass vials filled with water and sealed with parafilm were exposed to whitefly populations for seven days and then transferred into cup cages for another seven days as above. Infested leaves were inspected to assure that an excess of all instars was present before being enclosed individually in Petri dishes $(8 \times 1.2 \mathrm{~cm})$ into which a single parasitoid couple was introduced for $24 \mathrm{~h}$. Nymphs were then inverted by instar to determine whether or not a parasitoid egg was present under each.

Development time of immature stages

Rooted sweet potato slips in $7.6 \mathrm{~cm}$ pots placed in the whitefly colony for $24 \mathrm{~h}$ were covered with an inverted transparent plastic cup as above. Infested plants in individual cup cages were incubated in a growth chamber at $26^{\circ} \mathrm{C}, 60 \% \pm 6 \mathrm{RH}, 13: 11 \mathrm{~h}$ (L:D). After eight days, all leaves not containing whitefly nymphs were removed. Remaining leaves each contained between 50 and 100, 2nd and 3rd instar nymphs. Five parasitoids couples recently emerged and mated, were release in the experimental units for $15 \mathrm{~h}$. Immediately, and at subsequent $12-15 \mathrm{~h}$ intervals, 30 nymphs were removed from the leaves and eggs counted as above. Larvae including prepupae were dissected from the nymphs under the stereoscopic microscope to be counted and pupae were held individually in gel capsules until emergence. Development times of each stage were noted.

Mortality of immatures

Two collard plants (five leaves per plant) with 60, 2nd and 3rd instar nymphs per leaf were exposed to 50 couples of the parasitoid for $15 \mathrm{~h}$ to assure that most would be parasitized. After 11 days, when the parasitoid had reached the prepupal stage and mummies of the parasitized nymphs were clearly distinguishable, apparently unparasitized nymphs were inverted and undeveloped eggs and/or larvae counted, providing an estimate of mortality in those two stages. Finally, the number of adults that emerged from apparently parasitized nymphs was determined to provide an estimate of mortality in the pupal stage.

Fecundity and longevity

Pairs $(n=7)$ of newly emerged ( $15 \mathrm{~h}$ or less) female and male E. sudanensis were placed separately inside ventilated plastic Petri dishes with honey and water supplied daily. Collard leaves with a variable number (40-80) of 2nd and 3rd instar nymphs were offered daily to each pair until the female died. Males were replaced as needed. Number of nymphs offered and parasitized was recorded as above.

Demographic parameters

Values for age-specific survivorship beginning with eggs laid during the preceding $24 \mathrm{~h}$ interval and agespecific fecundity for females were used to construct life tables. The intrinsic rate of increase $\left(r_{m}\right)$ was computed using the Euler equation,

$\sum \mathrm{e}^{-\mathrm{rm}} \mathrm{L}_{\mathrm{x}} \mathrm{m}_{\mathrm{x}}$

where $L_{x}$ is survivorship of the original cohort over the age interval from day $x-1$ to day $x$, and $m_{x}$ is the mean number of female offspring produced per surviving female during the age interval $x$ (Birch 1948). Values of $m_{x}$ for the population were calculated from the mean number of eggs laid per female per day. Other parameters, including reproductive rate $\left(R_{O}\right)$ and generation time $(T)$ were calculated as described by Birch (1948) using a statistical jackknife program (Maia et al. 2000). Doubling time was calculated from the equation

$\mathrm{DT}=(\ln 2) / \mathrm{r}$

(Mackauer 1983). 
Statistical analysis

Data were subjected to analysis of variance with LSD used for mean separation contingent on $P<0.05$ (SAS Institute 2006).

\section{Results}

No-choice test (suitability)

When female E. sudanensis were confined to only one host instar on collard, almost no parasitoid eggs were found under 4th instars, while no significant differences were seen among the remaining instars $(\mathrm{F}=27.59 ; \mathrm{df}=3,39 ; P<0.0001)$ (Table 1). On sweet potato leaves, fourth instars were again least suitable by far for oviposition, but 1 st instars were less suitable than 2 nd or 3 rd instars $(F=12.44$; $\mathrm{df}=3,31 ; P<0.0001)$.

\section{Choice test (preference)}

In contrast to the no-choice test, female E. sudanensis given a choice of host instars to parasitize showed no preference among 1st, 2nd and 3rd instars on either collard or sweet potato $\mathrm{F}=1.26 ; \mathrm{df}=2,29$; $P>0.2996$ and $\mathrm{F}=2.45 ; \mathrm{df}=2,29 ; P>0.1049$, respectively) (Table 2). No parasitoid eggs were found under 4th instar whitefly nymphs.

Biology and development time

Eggs of E. sudanensis appeared tiny, spherical, white and translucent. The initial larval stages were also almost spherical in shape and translucent (Fig. 1). As with other Eretmocerus species, the female lays a single egg on the surface of the leaf just under the whitefly nymph. After eclosion under a 2nd or 3rd instar host, the larva adheres to the ventral side of the nymph and immediately initiates the process of parasitism by penetrating and consuming host body fluids. However, when the egg is laid under the 1st instar, eclosion and adhesion did not occur until after the nymph molts to the second instar. One or two layers of the nymphal exuvia could be seen adhering to but not covering the larva completely and were easily separated and removed by dissection. When the host body contents had been consumed, the prepupal stage is distinguishable by its pear shape and differentiated head. Pupae are yellow with visible red eyes and the males are recognizable by the dark brown antennal pedicel.

Table 1 Mean \pm SE B. tabaci Biotype B nymphs exposed and parasitized by E. sudanensis during no-choice tests on collard seedlings $(n=10)$ or sweet potato slips $(n=8)$

\begin{tabular}{|c|c|c|c|c|}
\hline \multirow[t]{2}{*}{ Host nymphal stage } & \multicolumn{2}{|l|}{ Collard } & \multicolumn{2}{|l|}{ Sweet potato } \\
\hline & Hosts exposed & Parasitized & Hosts exposed & Parasitized \\
\hline $1 \mathrm{st}$ & $68.1 \pm 9.89$ & $16.6 \pm 1.82 \mathrm{a}$ & $58.8 \pm 9.35$ & $10.5 \pm 2.16 b$ \\
\hline 2nd & $68.8 \pm 6.52$ & $20.1 \pm 1.85 \mathrm{a}$ & $46.0 \pm 5.03$ & $20.0 \pm 3.86 \mathrm{a}$ \\
\hline $3 r d$ & $42.3 \pm 3.21$ & $17.6 \pm 2.07 \mathrm{a}$ & $42.8 \pm 3.86$ & $18.5 \pm 2.52 \mathrm{a}$ \\
\hline 4th & $58.2 \pm 5.26$ & $0.7 \pm 0.47 \mathrm{~b}$ & $36.3 \pm 5.45$ & $0.4 \pm 0.26 \mathrm{c}$ \\
\hline
\end{tabular}

Means followed by the same letter are not significantly different. $P<0.05$ (LSD test)

Table 2 Mean \pm SE of host B. tabaci Biotype B nymphs parasitized by E. sudanensis when provided a choice between 1st, 2nd and 3rd instars in choice tests on collard and sweet potato $(n=10)$ for both

\begin{tabular}{|c|c|c|c|c|}
\hline \multirow[t]{2}{*}{ Host nymphal stage } & \multicolumn{2}{|l|}{ Collard } & \multicolumn{2}{|l|}{ Sweet potato } \\
\hline & Hosts exposed & Parasitized & Hosts exposed & Parasitized \\
\hline $1 \mathrm{st}$ & $17.8 \pm 3.12$ & $3.5 \pm 0.47 \mathrm{a}$ & $46.3 \pm 9.80$ & $4.3 \pm 1.25 \mathrm{a}$ \\
\hline 2nd & $14.3 \pm 3.18$ & $2.6 \pm 0.89 \mathrm{a}$ & $49.8 \pm 8.66$ & $7.2 \pm 1.20 \mathrm{a}$ \\
\hline $3 r d$ & $7.5 \pm 1.42$ & $2.1 \pm 0.40 \mathrm{a}$ & $32.1 \pm 7.43$ & $4.0 \pm 0.89 \mathrm{a}$ \\
\hline
\end{tabular}

Means followed by the same letter are not significantly different. $P<0.05$ (LSD test) 


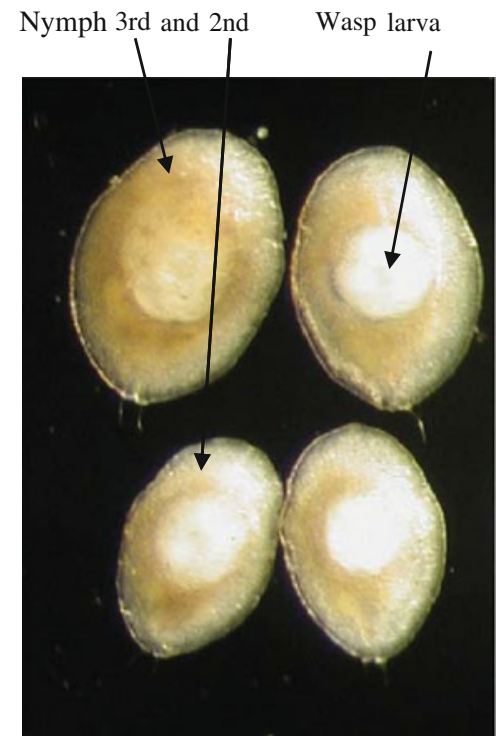

Fig. 1 Second and third instar nymphs of B. tabaci Biotype B parasitized by Eretmocerus sudanensis. Note the nymphs are almost completely consumed by the parasitoid larva (spherical form inside the host)

Table 3 Development time in days (mean \pm SE) of Eretmocerus sudanensis in B. tabaci Biotype $\mathrm{B}$ on sweet potato $\left(26^{\circ} \mathrm{C} \pm 0.5,62 \% \pm 6 \mathrm{RH}\right.$ and 13:11 L:D)

\begin{tabular}{lcccc}
\hline & No. & Mean (SE) & Min & Max \\
\hline Egg & 27 & $2.8 \pm 0.04$ & 2.6 & 3.0 \\
Larva & 17 & $8.5 \pm 0.06$ & 7.6 & 8.6 \\
Prepupa & 90 & $1.9 \pm 0.06$ & 0.10 & 2.10 \\
Pupa & 77 & $2.7 \pm 0.17$ & 1.20 & 6.20 \\
Total & 211 & $16.0 \pm 0.33$ & 11.5 & 19.9 \\
Sex ratio (female biased) & 0.71 & & & \\
\hline
\end{tabular}

Under our laboratory experimental conditions, the immature stages of E. sudanensis completed development in an average of 16 days with a minimum of 11.5 and a maximum of 19.9. Sex ratio was 0.71 female biased (Table 3).

Immature mortality

Total mortality over all immature stages of this parasitoid was estimated at $20 \pm 4 \%$ under our experimental conditions. Most mortality occurred in the larval stage $(11.3 \pm 3 \%)$, compared to $6.9 \pm 1 \%$ estimated for the egg stage and $1.9 \pm 0.6 \%$ for the pupal stage.
Table 4 Life history parameters of Eretmocerus sudanensis when reared on B. tabaci Biotype B on sweet potato $\left(26^{\circ} \mathrm{C} \pm 0.5,62 \% \pm 6 \mathrm{RH}\right.$ and 13:10 L:D)

\begin{tabular}{lcll}
\hline & Mean \pm SE & Max & Min \\
\hline Fecundity (lifetime) & $160.8 \pm 18.0$ & 220 & 125 \\
Fecundity (per day) & $12.7 \pm 1.5$ & 15.7 & 7.8 \\
Longevity female & $13.2 \pm 1.6$ & 17 & 9 \\
Longevity male & $8.0 \pm 1.14$ & 10 & 4 \\
\hline
\end{tabular}

Fecundity and longevity

The average longevity of adult E. sudanensis females was estimated at 13.2 (min. 9, max. 17) days during which time a mean 161 (min. 125, max. 220) eggs were laid (Table 4). Oviposition averaged 12.7 (min. 8, max. 16) eggs per day over the entire lifespan, proceeding at relatively constant rate until the 14th day (Fig. 2). Average male survival was eight days.

\section{Demographic parameters}

Demographic parameters calculated from life table data demonstrated a great reproductive potential for E. sudanensis (Table 5). Comparisons with congeners are given in the discussion below.

\section{Discussion}

The intermediate host stages (2nd and 3rd) proved to be most suitable for oviposition by E. sudanensis as with other parasitoids of the same genus: E. mundus (Urbaneja and Stansly 2004), E. melanoscutus (Liu 2007). However, no difference in preference was seen between 1st instars and the next two host stages for either plant host, even though 1st instars proved less suitable on sweet potato. However, eggs laid under 1 st instars did not eclose until the 2nd instar which in fact became the host. No eggs were found under 4 th instar nymphs regardless of plant host during choice tests and few during no-choice tests, indicating that the last instar was not suitable for either oviposition or development of progeny although early 4th instars may be used by E. mundus (Gelman et al. 2005). These traits were seen with either collard or sweet potato as host plant. 
Fig. 2 Survivorship of E. sudanensis females and mean $(+\mathrm{SE})$ number of eggs oviposited into late 2nd and early 3rd instars of B. tabaci Biotype B under laboratory conditions of $26^{\circ} \mathrm{C} \pm 0.5,62 \% \pm 6 \mathrm{RH}$ and 13:11 h (L:D)

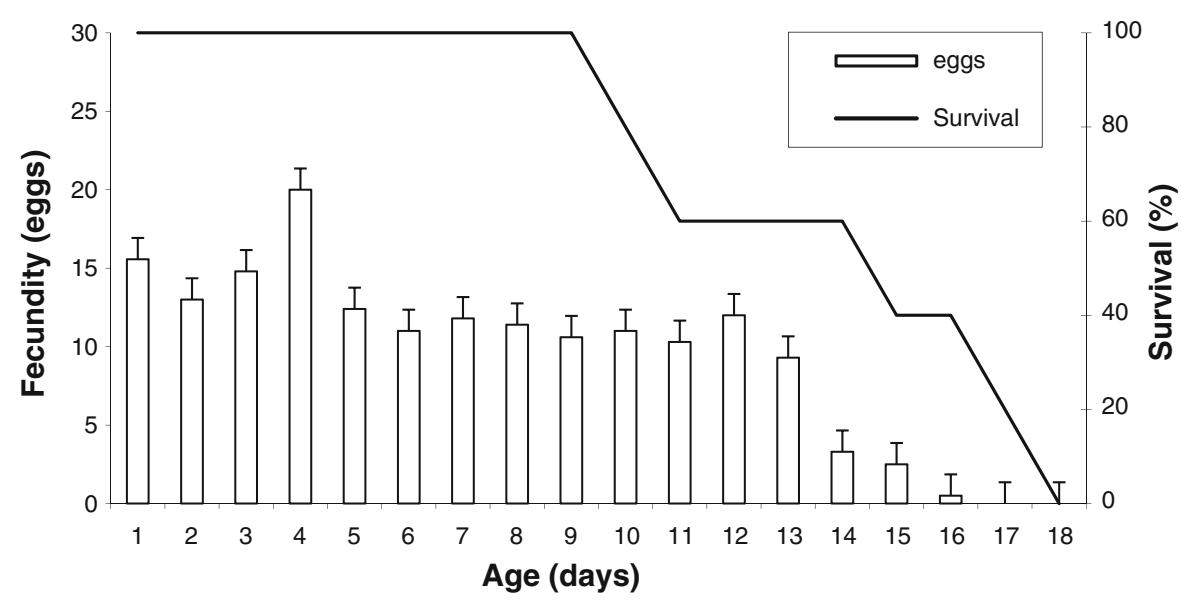

Table 5 Jackknife estimates and respective confidence limits of demographic parameters for E. sudanensis parasitizing $B$. tabaci Biotype B under laboratory conditions: $26^{\circ} \mathrm{C} \pm 0.5,62 \% \pm 6 \mathrm{RH}$ and 13:10 L:D

\begin{tabular}{lllc}
\hline Parameter & Value & Unit & $95 \%$ Confidence limits \\
\hline Net reproductive rate $\left(\mathrm{R}_{\mathrm{o}}\right)$ & 91.3 & Eggs/female & $62.9-119.8$ \\
Generation time $(\mathrm{T})$ & 18.5 & Days & $17.3-19.6$ \\
Doubling time $(\mathrm{DT})$ & 2.8 & Days & $2.7-3.0$ \\
Intrinsic rate of increase $\left(\mathrm{r}_{\mathrm{m}}\right)$ & 0.24 & Per day & $0.23-0.26$ \\
Finite rate of increase $(\lambda)$ & 1.28 & Per day & $1.26-1.30$ \\
\hline
\end{tabular}

Gelman et al. (2005) reported that the E. mundus 1 st instar larva only penetrates when the host reaches 4th instar, and that encapsulation of the larva was often observed subsequently. In the case of E. sudanensis, we observed penetration taking place in the 2 nd and 3rd instars, with continual development of the larva despite subsequent host molting (Fig. 1). Melanization of the egg and larva as an indication of encapsulation was not observed. Copland (1976) indicated that encapsulation is not typical of the Aphelinidae and some groups of this family are able to prevent the encapsulation of its hosts. Nevertheless, encapsulation of E. mundus as described by Gerling et al. $(1990,1991)$ is not characterized by melanization. The E. sudanensis larva could thus be encapsulated by this non-melanizing process or 2nd and 3rd instar hosts which are penetrated by E. sudanensis, in contrast to E. mundus, may not react to parasitoid-induced cues for capsule formation as suggested by Gelman et al. (2005).

Our results also suggested distinctions between E. sudanensis and other Eretmocerus species attacking B. tabaci, although such comparisons may be problematic because of differences among studies in host stage, host plant, and ambient conditions. We estimated a value of 16 days for preimaginal development time in a mixture of 2nd and 3rd instars of E. sudanensis at $26^{\circ} \mathrm{C}$ and $13 \mathrm{~h}$ light, compared 22.6 days for E. eremicus at $28^{\circ} \mathrm{C}$ (Headrick et al. 1999), 19.8 days (2nd instar host) and 16.8 days (3rd instar host) for E. melanoscutus parasitizing $B$. tabaci biotype $\mathrm{B}$ at $26.7^{\circ} \mathrm{C}$ at $16 \mathrm{~h}$ light (Liu 2007), and 17.1 days at $25^{\circ} \mathrm{C}$ and $16 \mathrm{~h}$ light for E. mundus parasitizing B. tabaci biotype Q (Urbaneja et al. 2006). No preoviposition period was observed for E. sudanensis as with E. mundus (Urbaneja et al. 2006) and E. melanoscutus, whereas 0.61 days was reported for E. eremicus (Headrick et al. 1999). Female E. sudanensis lived an average of 13.2 days and in this time deposited an average of 161 eggs at a mean oviposition rate of 13 eggs per day, comparing favorably with E. eremicus (5.0 days, 23 eggs and 5.6 eggs per day) and E. melanoscutus (10.7 days, 122 eggs and 11.2 eggs per day) and was similar to E. mundus (8.5-10.5 days, 148-171 eggs, and 19.2 eggs per day, tomato and pepper, respectively). 
Since its introduction in 1990, E. sudanensis not only appears to have spread and established in several Florida counties, but also to have largely, if not completely, replaced the native Eretmocerus sp. This could happen if its population growth rate, as summarized by the exponential intrinsic rate of increase $\left(r_{m}\right)$, were more favorable in this environment. We estimated an $\mathrm{r}_{\mathrm{m}}$ for E. sudanensis of 0.24 on sweet potato compared to 0.106 reported by Headrick et al. (1999) for E. eremicus. The latter species is closely related to the native Florida species which keys to E. eremicus or the almost indistinguishable E. tejanus (Stansly et al. 1997; Rose and Zolnerowich 1997). Thus, populations of E. sudanensis on $B$. tabaci would be predicted to increase more rapidly by an order of magnitude than E. eremicus, providing a tremendous advantage to the introduced parasitoid.

We also found a net reproductive rate (Ro) of 91.3 eggs/female and a generation time ( $T$ ) of 18.5 days which along with the intrinsic rate of increase mentioned above also appear superior to an Ro of 63.8, and 51.0 and $\mathrm{r}_{\mathrm{m}}$ of 0.216 and 0.219 reported for E. mundus on sweet pepper and tomato, respectively, by Urbaneja et al. (2006). Similarly, Liu (2007) observed an Ro of 61.4 eggs/female and an $r_{m}$ of 0.217 for another Old World species E. melanoscutus which itself compared favorably to other Eretmocerus species.

The superior performance of Old World species of Eretmocerus such as E. mundus, E. melanoscutus and E. sudanensis on B. tabaci may be due to the fact that New World species, exemplified by E. eremicus, are less specialized on this host. It is little wonder that Old World Eretmocerus have supplanted New World species wherever the former have been released to control B. tabaci in the USA. Naturally, there are other characteristics that may influence the value of a biological control agent in an agricultural setting, such as tolerance to extreme environmental conditions, adaptability to different crops, etc. Hopefully, continued research will reveal more unique characteristics of these aphelinid species that can be exploited to provide better biological control of B. tabaci. Difficulties with female sterility recently encountered in mass rearing of E. mundus (K. Bolckmans, S. Steinberg, personal communication) should provide further motivation to look toward other Old World species to serve as alternatives for augmentative biological control of B. tabaci. Eretmocerous sudanensis may be a good candidate due to its high reproductive capacity and demonstrated adaptability to a range of environments.

Acknowledgments We thank Mauricio Pinto for providing technical assistance in the Whitefly and parasitoid colonies maintenance and S. Naranjo, D. Gerling and A. Urbaneja for helpful suggestions to earlier drafts of this document. Research was supported in part by the University of Florida Integrated Pest Management (EIPM-CS) Project Number 00078485, National Institute of Food and Agriculture.

Open Access This article is distributed under the terms of the Creative Commons Attribution Noncommercial License which permits any noncommercial use, distribution, and reproduction in any medium, provided the original author(s) and source are credited.

\section{References}

Birch LC (1948) The intrinsic rate of natural increase of an insect population. J Anim Ecol 17:16-26

Copland MJW (1976) Female reproductive system of the Aphelinidae (Hymenoptera: Chalcidoidea). Int J Insect Morphol Embryol 5(3):151-166

Gelman DB, Gerling D, Blackburn MA (2005) Host-parasite interactions relating to penetration of Bemisia tabaci by its parasitoid Eretmocerus mundus. J Insect Sci 5:46

Gerling D, Orion T, Delarea Y (1990) Eretmocerus penetration and immature development: a novel approach to overcome host immunity. Arch Insect Biochem Physiol 13:247-253

Gerling D, Tremblay E, Orion T (1991) Initial stages of the vital capsule formation in the Eretmocerus-Bemisia tabaci association. Insect parasitoids-4th European workshop, Perugia April 3-5 1991. Redia 74:411-415

Gould J, Waldner D, Colletto N, Merten P (2008) Release and recovery of four species of Eretmocerus against Bemisia tabaci Biotype B in Arizona. In: Gould J, Hoelmer K, Goolsby J (eds) Classical biological control of Bemisia tabaci in the United States: a review of interagency research and implementation, HMT Hokkanen (series ed.) Progress in biological control V4. Springer, Dordrecht, pp 191-204

Headrick DH, Bellows TS, Perring TM (1999) Development and reproduction of a population of Eeretmocerus eremicus (Hymenoptera: Aphelinidae) on Bemisia argentifolii (Homoptera: Aleyrodidae). Environ Entomol 28:300-306

Hoelmer KA, Roltsch WJ (2008) Evaluation of exotic parasitoids and predators in field cages in California. In: Gould J, Hoelmer K, Goolsby J (eds) Classical biological control of Bemisia tabaci in the United States: a review of interagency research and implementation, HMT Hokkanen (series ed.) Progress in biological control V4. Springer, Dordrecht, pp 129-145

Liu TX (2007) Life history of Eretmocerus melanoscutus (Hymenoptera: Aphelinidae), parasitizing nymphs of 
Bemisia tabaci Biotype B (Homoptera: Aleyrodidae). Biol Control 42:77-85

Mackauer M (1983) Quantitative assessment of Aphidius smithi (Hymenoptera: Aphidiidae): Fecundity, intrinsic rate of increase, and functional response. Can Entomol 115: $399-415$

Maia A de H, Luiz AJB, Campanhola C (2000) Statistical inference on associated fertility life table parameters using Jackknife technique: computational aspects. J Econ Entomol 93:511-518

Nguyen R, Bennett FD (1995) Importation and field release of parasites against silverleaf whitefly, Bemisia argentifolia (Bellows and Perring) in Florida from 1990-1994. Proc Florida State Hort Soc 108:43-47

Quaintance AL (1900) Contribution towards a monograph of the American Aleurodidae. Tech Ser US Dept Agric Bull Entomol 8:9-64

Roltsch WJ, Hoelmer KA, Simmons GS, Andress E (2008) Release and recovery of exotic natural enemies of Bemisia tabaci (Biotype "B") (Hemiptera: Aleyrodidae) in Imperial Valley, California In: Gould J, Hoelmer K and Goolsby J (eds.) Classical biological control of Bemisia tabaci in the United States: a review of interagency research and implementation, HMT Hokkanen (series ed.) Progress in biological control V4, Springer, Dordrecht, The Netherlands, pp 205-224

Rose M, Zolnerowich G (1997) Eretmocerus Haldeman (Hymenoptera: Aphelinidae) in the United States, with descriptions of new species attacking Bemisia (tabaci complex) (Homoptera: Aleyrodidae). Proc Entomol Soc Wash 99:1-27

SAS Institute (2006) SAS User's Guide: Statistics. Version 8.2 ed. SAS Institute, Inc., Cary
Schuster DJ, Evans GA, Bennett FD, Stansly PA, Jansson RK, Leibee GL, Webb SE (1998) A survey of parasitoids of Bemisia spp. Whiteflies in Florida, the Caribbean, and Central and South America. Int J Pest Manag 44(4):255-260

Stansly PA, Naranjo SE (eds) (2010) Bemisia bionomics and management of a global pest. Springer, Dordrecht, p 540

Stansly PA, Schuster DJ, Liu TX (1997) Apparent parasitism of Bemisia argentifolii (Homoptera: Aleyrodidae) by Aphelinidae (Hymenoptera) on vegetable crops and associated weeds in south Florida. Biol Control 9:49-57

Urbaneja A, Stansly PA (2004) Host suitability of different instars of the whitefly Bemisia tabaci 'Biotype Q' for Eretmocerus mundus. BioControl 49:153-161

Urbaneja A, Sanchez E, Stansly PA (2006) Life history of Eretmocerus mundus Mercet (Hym Aphelinidae), a parasitoid of Bemisia tabaci Gennadius (Hom. Aleyrodidae), on tomato and sweet pepper. BioControl 52:25-39

Vacek DC, Ruiz RA, Cimperlik MA, Goolsby JA (2008) Molecular characterization with RAPD-PCR: application of genetic diagnostics to biological control of the sweet potato whitefly. In: Gould J, Hoelmer K, Goolsby J (eds) Classical biological control of Bemisia tabaci in the United States: a review of interagency research and implementation, HMT Hokkanen (series ed.) Progress in biological control V4. Springer, Dordrecht, pp 11-128

Zolnerowitz G, Rose M (2008) The Genus Eretmocerus In: Gould J, Hoelmer K and Goolsby J (eds.) Classical biological control of Bemisia tabaci in the United States: a review of interagency research and implementation, HMT Hokkanen (series ed.) Progress in biological control V4. Springer, Dordrecht, pp 89-110 